\title{
Metabolic syndrome and psoriasis: a study in 97 patients
}

\author{
Lana Bassi Ferdinando BsC \\ Paula Kaori Fukumoto BsC \\ Sarah Sanches, $M D^{2}$ \\ Lincoln Helder Zambaldi Fabricio $M D^{2}$ \\ (iD) Thelma L Skare MD, PhD
}

\begin{abstract}
1. Faculdade Evangélica de Medicina do PR (Fepar - Medicine Evangelic College of Paraná) 2. Serviço de Dermatologia do Hospital Universitário Evangélico de Curitiba (Huec - Dermatology Service of the Evangelic University Hospital of Curitiba) 3. Serviço de Reumatologia do Hospital Universitário Evangélico de Curitiba (Huec - Rheumatology Service of the Evangelic University Hospital of Curitiba)
\end{abstract}

http://dx.doi.org/10.1590/1806-9282.64.04.368

\section{SUMMARY}

BACKGROUND: Psoriasis is associated with higher prevalence of metabolic syndrome (MS). The prevalence of MS varies according to the studied population as it suffers influence of genetics, aging, sedentary behaviour and diet.

OBJECTIVE: To study the prevalence of MS in local psoriasis patients and the influence of psoriasis variables on its appearance.

METHODS: A group of 97 psoriasis patients were studied for MS and compared with 97 controls. Psoriasis type, nail involvement, psoriasis extension measured by PASI (Psoriasis Area and Severity Index) were obtained through physical examination and history of previous myocardial infarction, angina and stroke were obtained through chart review.

RESULTS: Comparison of MS prevalence in psoriasis patients (49.4\%) with controls (35.0\%) showed difference with $p=0.04$; OR=1.8 (95\% Cl=1.02-3.23). Patients with psoriasis had higher body mass index ( $p=0.02)$, higher systolic blood pressure ( $p=0.007)$, lower $\mathrm{HDL}$ cholesterol $(p=0.01)$, higher glucose $(p=0.04)$, higher waist circumference $(p=0.003)$ and more angina pectoris $(p=0.03 ; 0 R=2.5 ; 95 \%$ $\mathrm{Cl}=1.04-6.15)$ than controls. When psoriasis sample with and without MS were compared, those with MS were older ( $p=0.0004)$, had disease onset at older age $(p=0.02)$, more tobacco exposure $(p=0.02)$, and a tendency to have less scalp involvement $(p=0.06)$ in univariate analysis. Logistic regression showed that only age and scalp involvement were independently associated with MS in the psoriasis sample.

CONCLUSION: In our psoriasis sample, MS prevalence is high and the items that deserve more attention are central obesity, low HDL, hypertension and smoking habits. In the psoriasis group, MS was associated independently with older age and less scalp involvement.

KEYWORDS: Psoriasis. Metabolic syndrome X. Metabolic diseases.

\section{INTRODUCTION}

Psoriasis is a chronic and complex immune-mediated skin disorder. ${ }^{1}$ The systemic nature of the inflammatory process involved in its etiopathogenesis is responsible for several co-morbidities, which themselves have a considerable impact on the patient's quality of life and mortality. ${ }^{1}$ Myocardial infarction and stroke are considered to be increased in patients with psoriasis when compared with the general population. ${ }^{2}$ Hence, the effective treatment of this disease includes not only care with the skin and nail manifestations but also attention to the associated conditions. A meta-analysis including 12 other studies showed that patients with psoriasis were 2.2 times more likely to have metabolic syndrome (MS) than the general population ${ }^{2}$ and some authors found that there is a positive correlation between severity of

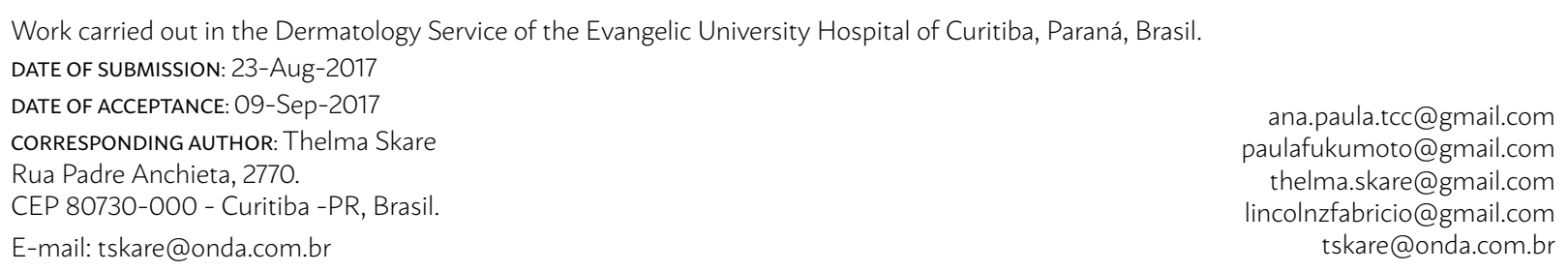

ana.paula.tcc@gmail.com paulafukumoto@gmail.com thelma.skare@gmail.com lincolnzfabricio@gmail.com tskare@onda.com.br 
psoriasis and the presence of MS. ${ }^{3}$ The exact mechanism for this interaction remains uncertain but the link between them may be the effects of pro-inflammatory cytokines and adipocytes on glucose regulation, lipid status, and endothelial function. ${ }^{1}$

MS is a clustering of several medical conditions such as central obesity, arterial hypertension, glucose intolerance, high serum triglycerides and low high-density lipoprotein (HDL) levels (4). It has been recognized as a pro-inflammatory, prothrombotic state associated with elevated levels of C-reactive protein (CRP), interleukin (IL)-6, and plasminogen activator inhibitor (PAI)-1., 5 This syndrome lies in the background of the association of psoriasis, cardiovascular risk and type 2 diabetes mellitus. The prevalence of MS varies according to the studied population as it suffers influence of genetics, aging, sedentary behaviour and diet. ${ }^{7,8}$

In the present study, we aimed at identifying the prevalence of MS in psoriasis patients from a single dermatology centre in Southern Brasil, and its relationship to the clinical profile of the skin disease.

\section{METHODS}

The local Committee of Ethics in Research approved this study and all participants signed a consent form. It is a cross sectional observational study that includes a convenience sample of 97 individuals formed by all psoriasis patients that came for regular consultations during a twelve-month period and that agreed to participate. All of them were from a single Dermatology Outpatient Clinic of a Tertiary Care Hospital. Patients under 18 years of age, pregnant women and patients with uncontrolled hypothyroidism were excluded. As control, 97 individuals were included, paired according to gender and age that came for an ophthalmologic appointment to test refraction and for routine gynaecological exams without chronic inflammatory diseases.

Epidemiological information (age, ethnic background, disease duration, tobacco use and age at disease onset), clinical aspects of psoriasis (psoriasis type, nail involvement, treatment), history of diabetes mellitus and high blood pressure treatment, previous history of myocardial infarction, angina and stroke were obtained through chart review and upon direct questioning. Data on PASI (Psoriasis Area and Severity Index) (9), arterial blood pressure, body mass index (BMI) and abdom- inal circumference were obtained through physical examination. Blood was drawn for fasting glucose (by automated enzymatic method), total cholesterol, HDL (high-density lipoprotein) cholesterol, LDL (low-density lipoprotein) cholesterol and triglycerides (by enzymatic/colorimetric methods); ESR (erythrocyte sedimentation rate by the Westergren method), uric acid (by fasting automated enzymatic method) and CRP (C reactive protein by immunoturbidimetry) were determined.

The metabolic syndrome diagnosis was done according to the guidelines developed by the 2001 NCEP ATP III and updated in 2005 in a statement from the American Heart Association (AHA)/National Heart, Lung, and Blood Institute (NHLBI) $(4,10)$. Current ATP III criteria define metabolic syndrome as the presence of any three of the following five traits:

- Abdominal obesity, defined as a waist circumference in men $\geq 102 \mathrm{~cm}$ and in women $\geq 88 \mathrm{~cm}$;

- Serum triglycerides $\geq 150 \mathrm{mg} / \mathrm{dL}$ or drug treatment for elevated triglycerides;

- HDL cholesterol $<40 \mathrm{mg} / \mathrm{dL}$ in men and $<50 \mathrm{mg} /$ $\mathrm{dL}$ in women or drug treatment for low HDL cholesterol;

- Blood pressure $\geq 130 / 85 \mathrm{mmHg}$ or drug treatment for elevated blood pressure;

- Fasting plasma glucose $\geq 100 \mathrm{mg} / \mathrm{dL}$ or drug treatment for elevated blood glucose.

\section{STATISTICAL ANALYSIS}

Data was collected in frequency and contingency tables. Data distribution was studied through the Kolmogorov Smirnov test. Central tendency was expressed in mean and standard deviation (SD) for parametrical data and median and interquartile range (IQR) for non-parametric data. Comparison studies were carried out through Fisher and chisquared test when data were nominal and Mann Whitney and unpaired t test when data were numeric. Correlation studies were carried out through the Spearman test.

Data that showed association/correlation with $\mathrm{p}<0.1$ with MS in univariate analysis were further studied through logistic regression (MS as dependent variable) to access the variables independence.

The adopted significance level was 5\%. Calculations were done with the help of the software Medcalc 12.0. 


\section{RESULTS}

Pairing data and sample description:

In the 97 psoriasis patients, 48/97 (49.4\%) were female with age range between 20 and 80 years old (median=52; IQR=42-59 years); in the 97 individuals from the control group, 49/97 (50.5\%) were female $(\mathrm{p}=0.94)$; with age range between 20 and 81 years old (median=52; IQR=31.5-60; $\mathrm{p}=0.44$ ).

In the psoriasis group, the age of disease onset varied from 6-72 years old (mean 30.9 \pm 16.2 years) and the disease duration was of 1-43 years (median 13.0; IQR=8-21.5 years). Tobacco exposure was found in $61.8 \%$ of them. Tobacco use was more common in psoriasis patients $(28.8 \%$ smokers and $32.2 \%$ former smokers) than controls $(6.2 \%$ smokers and $23.7 \%$ former smokers) with $\mathrm{p}<0.0001$.

In 81/97 (83.5\%) the psoriasis was in plaques; in 10/97 (10.3\%) it was gutatta; in 5/97 (5.1) it was pustular, in 4/97(4.1\%) involved genital area; in 33/97 (34.0\%) involved scalp; in 10/97 (10.3\%) had articular involvement. Nail involvement was found in 27/97 (27.8\%) ranging from 1 to 20 fingers (median 5.0 ; IQR $=2-12$ ). PASI varied from 0 to 49.8 (median=3.4; IQR=1.6-10.0). This sample was treated with cyclosporine in $3.0 \%$; acitretin in $7.2 \%$; methotrexate in $28.8 \%$; ustekinumab in $7.2 \%$ and anti TNF- $\alpha$ drugs in $17.5 \%$. About $34.0 \%$ used just topical treatment.
Comparison of psoriasis patients and controls according to metabolic profile:

The MS prevalence, its components as well as its cardiovascular repercussions in the psoriasis group compared with controls are shown in Table 1. In this table, it is possible to see that psoriasis patients had higher rate of MS, higher BMI and waist circumference, higher systolic blood pressure and glucose level, lower HDL cholesterol and higher number of individuals with angina pectoris.

Comparison between psoriasis patients with and without MS:

When psoriasis patients with and without MS were compared, we noticed that those with MS were older, had higher exposure to tobacco, disease onset at older age and tendency towards less involvement of scalp as shown in Table 2.

When psoriasis variables associated with MS with $\mathrm{p}<0.1$ were studied through logistic regression, age (OR=1.08; 95\% CI=1.06-1.16) and scalp involvement $(\mathrm{OR}=0.23 ; 95 \% \mathrm{CI}=0.06-0.87)$ were independently related to MS.

\section{DISCUSSION}

The results of the present study have shown that psoriasis patients from our region have 1.8 times

TABLE 1 - COMPARISON OF METABOLIC SYNDROME, ITS COMPONENTS AND ITS CONSEQUENCES BETWEEN

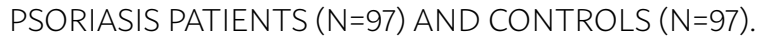

\begin{tabular}{|c|c|c|c|}
\hline Variable & Psoriasis patients & Controls & $P$ \\
\hline Metabolic syndrome - n (\%) & $48 / 97(49.4)$ & $34 / 97(35.0)$ & $0.04^{*} \S$ \\
\hline Mean body mass index and SD - (kg/m2) & $28.4 \pm 5.09$ & $26.8 \pm 4.68$ & $0.02^{*}$ \\
\hline Median systolic blood pressure and IQR - $(\mathrm{mm} \mathrm{Hg})$ & $130(120-140)$ & $120(110-130)$ & $0.007^{\star \star}$ \\
\hline Median diastolic blood pressure and IQR - $(\mathrm{mm} \mathrm{Hg})$ & $80(70-90)$ & $80(70-90)$ & $0.99^{\star \star}$ \\
\hline Median waist circumference and SD $(\mathrm{cm})$ & $99(92-108)$ & $94(86-104)$ & $0.003 \#$ \\
\hline History of hypertension $-\mathrm{n}(\%)$ & $37(38.1)$ & $43(44.3)$ & $0,38^{*}$ \\
\hline History of dyslipidemia- n (\%) & $23(23.7)$ & $23(23.7)$ & $1.00^{*}$ \\
\hline History of diabetes mellitus & $10(10.3)$ & $10(10.3)$ & $1.00^{*}$ \\
\hline History of angina pectoris & $18(18.5)$ & $8(8.2)$ & $0.003^{*} \S \S$ \\
\hline History of stroke & 0 & $1(1.03)$ & 1.00\#\# \\
\hline History of myocardial infarction & $4(4.1)$ & $5(5.1)$ & $1.00^{*}$ \\
\hline Median fasting blood glucose and SD (mg/dL) & $89(80-98.5)$ & $91.7(87-101)$ & $0.04 \# \#$ \\
\hline Median total cholesterol and IQR (mg/dL) & 181(160-203) & $180(160-212)$ & $0.52^{\star \star}$ \\
\hline Median HDL cholesterol and IQR (mg/dL) & $42(37.0-50.5)$ & $47(39.0-59.5)$ & $0.01^{\star \star}$ \\
\hline Median LDL Cholesterol and IQR (mg/dl) & 196.4(84-129.9) & $104(86-126)$ & $0.37^{\star \star}$ \\
\hline Median triglycerides and IQR (mg/dL) & $118(78-164.5)$ & 119.2(87-168) & $0.39^{* \star}$ \\
\hline
\end{tabular}

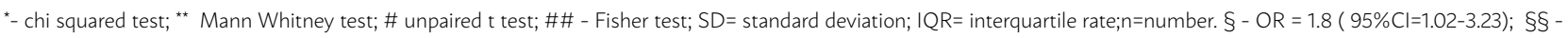
$\mathrm{OR}=2.5,95 \% \mathrm{Cl}=1.04-6.15)$. 
more chances of having MS than controls, a result similar to the findings of a meta-analysis done by Armstrong et $\mathrm{al}^{2}$ that included 41,853 patients. When comparing psoriatic patients with controls, the MS components that predisposed to this finding were body weight, waist circumference and high systolic blood pressure. Low HDL cholesterol and higher glucose levels were also a finding. Studies of the relationship between the individual components of MS with psoriasis are contradictory. Madanagobalane and Anandan ${ }^{3}$ reported a higher prevalence of obesity in psoriasis patients than in controls as we did, but Nisa and Qazi ${ }^{11}$, contrasting with our findings, did not observe a difference in the occurrence of central obesity. Finding a higher prevalence of central obesity is important in this context because it has become clear that the distribution and function of adipose tissue, rather than the amount of fat per se, exerts an important impact in MS. ${ }^{12}$ A strong genetic component influencing fat distribution has been described and may be responsible for the contradictory findings in populations with different ethnic backgrounds. ${ }^{13}$

Hypertension is another component of MS. While some studies have shown an association between hypertension and psoriasis, others have not ${ }^{3,14-18}$. In our study, the number of patients with hypertension was the same in controls and psoriasis but systolic blood pressure was higher in the psoriatic group.

Low HDL serum levels contribute to cardiovascular risk in this context as this particle has multiple anti-atherogenic properties. ${ }^{15,19}$ Low serum HDL level may result in decreased activity of lipoprotein lipase, secondary to insulin resistance ${ }^{20}$. HDL anti-atherogenic properties are believed to be mediated by its role in the elimination of cholesterol from macrophages in a mechanism called "macrophage cholesterol efflux" ${ }^{19}$ It also hinders the thrombotic component of atherosclerosis ${ }^{21}$ and helps maintain the endothelial function. ${ }^{22}$ Its serum levels are inversely related to stroke risk, need for coronary revascular-

TABLE 2 - COMPARISON OF PSORIASIS PATIENTS WITH (N=48) AND WITHOUT (N=49) METABOLIC SYNDROME (MS).

\begin{tabular}{|c|c|c|c|}
\hline Variable & With MS & Without MS & $\mathrm{P}$ \\
\hline Gender (female/male) & $23 / 25$ & $25 / 24$ & $0.75^{*}$ \\
\hline Mean age and SD (years) & $54.9 \pm 10.6$ & $45.9 \pm 13.3$ & $0.0004 \#$ \\
\hline Median age at disease onset and IQR (years) & $44(33-63)$ & $31(16-43.5)$ & $0.002^{\star \star}$ \\
\hline Median disease duration and IQR (years) & $12(4.5-22.5)$ & $13(8-21.5)$ & $0.72^{\star \star}$ \\
\hline Ethnic background $(\mathrm{A} / \mathrm{C})$ & $6 / 42$ & $9 / 40$ & $0.57^{\star}$ \\
\hline Tobacco users $-\mathrm{n}(\%)$ & 35 (72.9) & $25(51)$ & $0.02^{*}$ \\
\hline Median ESR and IQR (mm) & $25(10-42)$ & $20(9-33)$ & $0.39^{* *}$ \\
\hline Median CRP and IQR (mg/dL) & $11.6(6-17.5)$ & $9.5(5,2-19.3)$ & $0.65^{* \star}$ \\
\hline Mean uric acid and SD (mg/dL) & $5.2 \pm 1.1$ & $4.9 \pm 1.1$ & $0.14 \#$ \\
\hline Presence of nail psoriasis - $\mathrm{n}(\%)$ & $16(33.3)$ & $12(24.4)$ & $0.33^{*}$ \\
\hline Median number of involved nails and IQR & $5(3.2-11.2)$ & $6(2-12)$ & $0.76 \# \#$ \\
\hline Vulgar psoriasis - n (\%) & $40(83.3)$ & $41(83.6)$ & $0.96^{\star}$ \\
\hline Psoriasis guttata - n (\%) & $3(6.2)$ & $7(14.2)$ & $0.31 \# \#$ \\
\hline Pustular psoriasis - n (\%) & $4(8.3)$ & $1(2.0)$ & $0.20 \# \#$ \\
\hline Genital involvement - n (\%) & $1(2.0)$ & $3(6.1)$ & $0.61 \# \#$ \\
\hline Scalp involvement - n (\%) & $12(25)$ & $21(42.8)$ & $0.06^{*}$ \\
\hline Articular involvement - n (\%) & $5(10.4)$ & $5(10.2)$ & $1.0 \# \#$ \\
\hline Median PASI and IQR & $3.4(1.2-7.3)$ & $3.5(1.6-10.0)$ & $0.51^{\star *}$ \\
\hline \multicolumn{4}{|l|}{ Treatment } \\
\hline Cyclosporine - n (\%) & $1(2.0)$ & $2(4.0)$ & 1.0 \#\# \\
\hline Acitretin - n (\%) & $4(8.3)$ & $3(6.1)$ & $0.71 \# \#$ \\
\hline Methotrexate - n (\%) & $16(33.3)$ & $12(24.4)$ & $0.33^{*}$ \\
\hline Ustekinumab - n (\%) & $2(4.1)$ & $5(10.2)$ & $0.43 \# \#$ \\
\hline Anti TNF- $\alpha-n(\%)$ & $8(16.6)$ & $9(18.3)$ & $0.82^{*}$ \\
\hline Only topic treatment $-\mathrm{n}(\%)$ & $16(33.3)$ & $17(34.6)$ & $0.88^{*}$ \\
\hline
\end{tabular}

*- chi squared test; ** Mann Whitney test; \# unpaired t test; \#\# - Fisher test; SD= standard deviation; IQR= interquartile rate; $\mathrm{n}=$ number; $\mathrm{ESR}=$ erythrocyte sedimentation rate; $C R P=S$ reactive protein; $A / C=$ Afrodescendants/Caucasians; PASI = Psoriasis Area Severity Index. 
ization, myocardial infarction and death from cardiovascular causes. ${ }^{15,19}$ Beneficial effects of psoriasis treatment on HDL composition and function were observed in a small uncontrolled study. ${ }^{23}$

Smoking habits have a close relationship with psoriasis: it is associated with higher prevalence and severity of this skin disease. ${ }^{24}$ The present study shows that, not only psoriasis patients smoke more than controls, but also that the prevalence of this practice was more common in psoriatic patients with MS. This practice certainly worsens the scenario. Smoking increases levels of triglycerides (TG) and lowers HDL cholesterol ${ }^{25}$; it also releases large amounts of free radicals causing oxidative stress. ${ }^{23}$ Smokers were found to have the largest waist circumference and reduced insulin sensitivity. ${ }^{26}$ The effect of smoking on metabolic disorders lasts up to 20 years after quitting the habit. ${ }^{27}$

Several authors have noted an association of progression of skin involvement ${ }^{2,3,28}$ and presence of the arthropatic form ${ }^{29}$ with SM. In our sample, it was not possible to link the presence of MS neither with the extension of the skin disease nor with articular manifestations. Our sample of patients with psoriatic arthritis was small and may not have had the strength to prove such association. Psoriatic arthritis occurs in 33\% of psoriasis patients in our region ${ }^{30}$ but it was present in roughly $10 \%$ of the studied sample. Concerning the occurrence of MS, according to the degree of skin involvement, it is important to note that categorizing severity of disease based on the percentage of affected body surface area may be a poor marker of the degree of systemic inflammation ${ }^{18}$, especially when all types of psoriasis are studied together. Most studies in the literature were done exclusively in patients with psoriasis vulgaris not including others forms as we did.

A curious feature in the present analysis was the negative association of scalp psoriasis with MS. In our sample, only one patient had isolated scalp involvement; all others had association with plaque psoriasis. We did not find data from others studies to compare with and this finding is a contribution of the authors to this issue.

In the current study, it was also not possible to prove that the medications used for treatment modified the scenario, including the use of biologic agents. Biological drugs may have a beneficial effect in this context ${ }^{31}$. The low sample number may have precluded this finding.

This is a transversal study with a small number of patients and all the limitations that this type of study has but it does show the urgent need for a holistic view in the care of psoriatic patients.

Concluding, in the studied sample, MS prevalence is high in the psoriasis patients and findings that deserve more attention are central obesity, low HDL, hypertension and smoking habits. As psoriasis is quite a common disease, with estimated prevalence of $2.5 \%$ in the general population in our country ${ }^{32}$, this brings a great opportunity for the dermatologist to act as a transforming agent by improving the survival rate of this group of patients.

\section{CONFLICT OF INTEREST}

None.

\section{RESUMO}

OBJETIVO: Estudar a prevalência de SM (Síndrome metabólica) em pacientes com psoríase de nossa localidade, assim como a influência das variáveis da psoríase no seu aparecimento.

MÉTODOS: Noventa e sete pacientes com psoríase foram estudados para SM e comparados com 97 controles. Dados sobre o tipo de psoríase, envolvimento de unhas e extensão da lesão cutânea medida pelo PASI (Psoriasis Area and Severity Index) foram obtidas por meio de exame físico. Dados de infarto do miocárdio, angina pectoris e acidente vascular cerebral prévios foram coletados por meio de revisão de prontuários e questionamento direto.

RESULTADOS: A comparação da prevalência de SM em pacientes com psoríase (49,4\%) com controles (35,0\%) apresentou diferença $\operatorname{com} p=0,04 ; O R=1,8(I C 95 \%=1,02-3,23)$. Pacientes com psoríase apresentaram maior índice de massa corporal $(p=0,02)$, maior pressão arterial sistólica $(p=0,007)$, menor colesterol HDL $(p=0,01)$, maiores valores de glicose $(p=0,04)$, maior circunferência da cintura ( $p=0,003)$ e mais angina pectoris ( $p=0,03 ; O R=2,5 ;$ IC95\% = 1,04-6,15) do que controles. Quando os pacientes de psoríase com e sem SM foram comparados entre si, aqueles com SM eram mais velhos ( $p=0,0004)$, apresentaram início da doença em idade mais avançada $(p=0,02)$, tinham maior exposição ao fumo $(p=0,02)$ e tendência a ter menor envolvimento no couro cabeludo ( $p=$ $0,06)$ quando comparados com os sem SM na análise univariada. A regressão logística mostrou que apenas a idade e o envolvimento do couro cabeludo foram independentemente associados à SM na amostra de psoríase. 
CONCLUSÃO: Na presente amostra de pacientes com psoríase, a prevalência de SM é alta e os itens que merecem mais atenção são obesidade central, baixo HDL, hipertensão e hábito de fumar. No grupo da psoríase, a SM foi associada de forma independente com idade mais avançada e menor envolvimento no couro cabeludo.

PALAVRAS-Chave: Psoríase. Síndrome metabólica. Doenças metabólicas.

\section{REFERENCES}

1. Kim GW, Park HJ, Kim HS, Kim SH, Ko HC, Kim BS, et al. Analysis of cardiovascular risk factors and metabolic syndrome in Korean patients with psoriasis. Ann Dermatol. 2012;24(1):11-5.

2. Armstrong AW, Harskamp CT, Armstrong EJ. Psoriasis and metabolic syndrome: a systematic review and meta-analysis of observational studies. J Am Acad Dermatol. 2013;68(4):654-62.

3. Madanagobalane S, Anandan S. Prevalence of metabolic syndrome in South Indian patients with psoriasis vulgaris and the relation between disease severity and metabolic syndrome: a hospital-based case-control study. Indian | Dermatol. 2012;57(5):353-7.

4. Alberti KG, Eckel RH, Grundy SM, Zimmet PZ, Cleeman JI, Donato KA et al; International Diabetes Federation Task Force on Epidemiology and Prevention; National Heart, Lung, and Blood Institute; American Heart Association; World Heart Federation; International Atherosclerosis Society; International Association for the Study of Obesity. Harmonizing the metabolic syndrome: a joint interim statement of the International Diabetes Federation Task Force on Epidemiology and Prevention; National Heart, Lung, and Blood Institute; American Heart Association; World Heart Federation; International Atherosclerosis Society; and Internationa Association for the Study of Obesity. Circulation. 2009;120(16):1640-5.

5. Ridker PM, Buring JE, Cook NR, Rifai N. C-reactive protein, the metabolic syndrome, and risk of incident cardiovascular events: an 8-year follow-up of 14719 initially healthy American women. Circulation. 2003;107(3):391-7.

6. Festa A, D'Agostino R Jr, Howard G, Mykkänen L, Tracy RP, Haffner SM, et al. Chronic subclinical inflammation as part of the insulin resistance syndrome: the Insulin Resistance Atherosclerosis Study (IRAS). Circulation. 2000;102(1):42-7.

7. Gennuso KP, Gangnon RE, Thraen-Borowski KM, Colbert LH. Dose-response relationships between sedentary behavior and the metabolic syndrome and its components. Diabetologia. 2015;58(3):485-92.

8. Park YW, Zhu S, Palaniappan L, Heshka S, Carnethon MR, Heymsfield SB. The metabolic syndrome: prevalence and associated risk factor findings in the US population from the Third National Health and Nutrition Examination Survey, 1988-1994. Arch Intern Med. 2003;163(4):427-36.

9. Oji V, Luger TA. The skin in psoriasis: assessment and challenges. The skin in psoriasis: assessment and challenges. Clin Exp Rheumatol. 2015;33(5 Suppl 93):S14-9.

10. Grundy SM, Cleeman II, Daniels SR, Donato KA, Eckel RH, Franklin BA, et al; American Heart Association; National Heart, Lung, and Blood Institute. Diagnosis and management of the metabolic syndrome: an American Heart Association/National Heart, Lung, and Blood Institute Scientific Statement. Circulation. 2005;112(17):2735-52.

11. Nisa N, Qazi MA. Prevalence of metabolic syndrome in patients with psoriasis. Indian | Dermatol Venereol Leprol. 2010;76(6):662-5.

12. InterAct Consortium, Langenberg C, Sharp SJ, Schulze MB, Rolandsson O, Overvad $\mathrm{K}$, et al. Long-term risk of incident type 2 diabetes and measures of overall and regional obesity: the EPIC-InterAct case-cohort study. PLoS Med. 2012;9(6):e1001230.

13. Heid IM, Jackson AU, Randall JC, Winkler TW, Qi L, Steinthorsdottir V, et al. Meta-analysis identifies 13 new loci associated with waist-hip ratio and reveals sexual dimorphism in the genetic basis of fat distribution. Nat Genet. 2010;42(1):949-60.

14. Huxley RR, Barzi F, Lam TH, Czernichow S, Fang X, Welborn T, et al; Asia Pacific Cohort Studies Collaboration and the Obesity in Asia Collaboration. Isolated low levels of high-density lipoprotein cholesterol are associated with an increased risk of coronary heart disease: an individual participant data meta-analysis of 23 studies in the Asia-Pacific region. Circulation. 2011;124(19):2056-64.
15. Sommer DM, Jenisch S, Suchan M, Christophers E, Weichenthal M. Increased prevalence of the metabolic syndrome in patients with moderate to severe psoriasis. Arch Dermatol Res. 2006;298(7):321-8.

16. Langan SM, Seminara NM, Shin DB, Troxel AB, Kimmel SE, Mehta NN, et al. Prevalence of metabolic syndrome in patients with psoriasis: a population-based study in the United Kingdom. | Invest Dermatol. 2012;132(3 Pt 1):556-62.

17. Love TJ, Qureshi AA, Karlson EW, Gelfand JM, Choi HK. Prevalence of the metabolic syndrome in psoriasis: results from the National Health and Nutrition Examination Survey, 2003-2006. Arch Dermatol. 2011;147(4):419-24

18. Kothiwala SK, Khanna N, Tandon N, Naik N, Sharma VK, Sharma S, et al. Prevalence of metabolic syndrome and cardiovascular changes in patients with chronic plaque psoriasis and their correlation with disease severity: A hospital-based cross-sectional study. Indian J Dermatol Venereol Leprol. 2016;82(5):510-8.

19. Rosenson RS, Brewer HB |r, Davidson WS, Fayad ZA, Fuster V, Goldstein I, et al. Cholesterol efflux and atheroprotection: advancing the concept of reverse cholesterol transport. Circulation. 2012;125(15):1905-19.

20. Taskinen MR. Lipoprotein lipase in diabetes. Diabetes Metab Rev. 1987;3(2):551-70.

21. Griffin JH, Kojima K, Banka CL, Curtiss LK, Fernández JA. High-density lipoprotein enhancement of anticoagulant activities of plasma protein $\mathrm{S}$ and activated protein C. J Clin Invest. 1999;103(2):219-27.

22. Kuhn FE, Mohler ER, Satler LF, Reagan K, Lu DY, Rackley CE. Effects of high-density lipoprotein on acetylcholine-induced coronary vasoreactivity. Am J Cardiol. 1991;68(15):1425-30.

23. Holzer $M$, Wolf $P$, Inzinger $M$, Trieb M, Curcic S, Pasterk L, et al. Anti-psoriatic therapy recovers high-density lipoprotein composition and function. | Invest Dermatol. 2014;134(3):635-42.

24. Naldi L, Mercuri SR. Smoking and psoriasis: from epidemiology to pathomechanisms. | Invest Dermatol. 2009;129(12):2741-3.

25. Ambrose JA, Barua RS. The pathophysiology of cigarette smoking and cardiovascular disease: an update. J Am Coll Cardiol. 2004;43(10):1731-7.

26. Wierzejewska R, Jarosz $M$. Is tobacco smoking an effective means of body weight control: review of literature. Przegl Lek. 2008;65(10):692-5.

27. Frati AC, Iniestra F, Ariza CR. Acute effect of cigarette smoking on glucose tolerance and other cardiovascular risk factors. Diabetes Care. 1996;19(2):112-8.

28. Pirro M, Stingeni L, Vaudo G, Mannarino MR, Ministrini S, Vonella M, et al. Systemic inflammation and imbalance between endothelial injury and repair in patients with psoriasis are associated with preclinical atherosclerosis. Eur J Prev Cardiol. 2015;22(8):1027-35.

29. Lin YC, Dalal D, Churton S, Brennan DM, Korman NJ, Kim ES, et al. Relationship between metabolic syndrome and carotid intima-media thickness: cross-sectional comparison between psoriasis and psoriatic arthritis. Arthritis Care Res (Hoboken). 2014;66(1):97-103.

30. Ranza R, Carneiro S, Qureshi AA, Martins G, Rodrigues J), Romiti R, et al. Prevalence of psoriatic arthritis in a large cohort of Brazilian patients with psoriasis. J Rheumatol. 2015;42(5):829-34.

31. Piérard GE, Piérard-Franchimont C, Szepetiuk G, Paquet P, Quatresooz $P$. The therapeutic potential of TNF-alpha antagonists for skin psoriasis comorbidities. Expert Opin Biol Ther. 2010;10(8):1197-208.

32. Duarte GV, Porto-Silva L, Oliveira MFP. Epidemiology and treatment of psoriasis: a Brazilian perspective. Psoriasis (Auckl). 2015;5:55-64. 